\title{
The Dynamics of Exhaled Aerosol Following the Usage of Heated Tobacco Product, Electronic Cigarette, and Conventional Cigarette
}

\author{
Marija Meišutovič-Akhtarieva, Tadas Prasauskas, Darius Čiužas, \\ Violeta Kaunelienė, Dainius Martuzevičius* \\ Department of Environmental Technology, Kaunas University of Technology, Lithuania
}

\section{ABSTRACT}

Heated tobacco products (HTPs) and electronic cigarettes (ECS) represent a potentially less harmful alternative to traditional tobacco products, such as conventional cigarettes (CCs), with growing popularity amongst adult smokers worldwide. Their users exhale a very dynamic aerosol to indoor air which undergoes rapid transformations. In the present study, we assessed the dynamics of the generated exhaled aerosols following use of a new HTP (branded as "Pulze", operating in eco and standard modes) and an e-cigarette ("myblu") in a chamber environment by three volunteers, controlling for the distance to bystander, ventilation intensity and microclimate. The HTP and EC data was compared against conventional cigarette data. HTP generally resulted in lower aerosol number concentration during puffs reaching $1.66 \mathrm{E}+06 \mathrm{\#} \mathrm{cm}^{-3}$ at $0.5 \mathrm{~m}$ from bystander, compared to EC (averaging $\left.4.3 \mathrm{E}+06 \mathrm{\#} \mathrm{cm}^{-3}\right)$, and CC $\left(1.47 \mathrm{E}+08 \mathrm{H} \mathrm{cm}^{-3}\right)$. No significant difference was observed between "eco" and "standard" modes of HTP. At the same time, EC concentration decrease after puffs was also faster, indicating higher volatility of particles. EC also featured higher mode during puff $(120 \mathrm{~nm})$ compared to HTP $(90 \mathrm{~nm})$, which was significantly different from conventional cigarette (165-200 nm). The evaporation/shrinkage of particles has been observed within $10 \mathrm{~s}$ after puff with the HTP and EC. Distance to a bystander was shown to be as a significant factor affecting aerosol dynamics, however ventilation intensity and relative humidity did not have statistically significant effect.

\section{OPEN ACCESS}

Received: December 8, 2020

Revised: March 7, 2021

Accepted: April 4, 2021

${ }^{*}$ Corresponding Author: dainius.martuzevicius@ktu.It

\section{Publisher:}

Taiwan Association for Aerosol Research

ISSN: $1680-8584$ print

ISSN: 2071-1409 online

Copyright: The Author's institution. This is an open access article distributed under the terms of the Creative Commons Attribution License (CC BY 4.0), which permits unrestricted use, distribution, and reproduction in any medium, provided the original author and source are cited.
Keywords: Indoor air quality, Nicotine containing products, Heated tobacco product, Electronic cigarette, Exhaled aerosol

\section{INTRODUCTION}

Over the past century, the number of worldwide smokers of tobacco products has increased to more than one and a half billion in the world (WHO, 2019). The usage of conventional cigarettes results in numerous hazardous pollutants emitted to ambient air and causes adverse health effects to both mainstream smokers and bystanders (Braun et al., 2019).

Alternative nicotine containing products have been intensively developed during past decade, aiming to replace burning/pyrolysis of tobacco with less harmful delivery of nicotine for the adult smoker. Vaping products, e.g., electronic cigarettes (ECs), and more recently heated tobacco products (HTPs) emerge as the options with the fastest market growth. While both of these technologies aim to reduce the generation of carcinogenic compounds in the mainstream aerosol, the operating principle is quite different. The mainstream aerosol from HTP is formed by distilling specially processed natural tobacco leaves using an electrically heated blade. Since the heating temperature is substantially lower than that of burning, the usual pyrolysis of tobacco does not occur, thus avoiding the formation of combustion byproducts (Smith et al., 2016). Electronic cigarette also utilizes heating principle to generate aerosol, but heats a vaping liquid consisting of nicotine (as opposed to nicotine in the tobacco matrix in HTPs) in an aerosol propellant matrix 
of known chemical composition (Gillman et al., 2016).

Both EC and HTP mainstream aerosol has been well characterized and has been shown to contain a complex mixture of nicotine, propellant, flavorings and other trace compounds (Schaller et al., 2016; Bekki et al., 2017; Jaccard et al., 2017). The HTP and EC aerosols also contain fewer and substantially lower levels of toxicants compared to CC smoke. The composition of aerosol may also depend on type of the device and heating regime, flavoring additives, operational voltage, and user puffing patterns (Allen et al., 2016; Floyd et al., 2018; Noël et al., 2018; Zhao et al., 2018; Gillman et al., 2020).

There is a limited amount of published data available on the impacts of the usage of these devices on indoor air quality, and subsequently, so-called "second-hand" exposure. Since no tobacco burning takes place, the primary source of pollution results from the exhaled breath of a product user. The composition of exhaled breath differs largely from the mainstream aerosol: The majority of exhaled particles are water-based, while most of nicotine is being absorbed in user's body (O'Connell et al., 2015; Mitova et al., 2019). However, a number of studies (as presented below) have indicated that the impact of EC usage and, to a lesser extent HTP, have a tangible impact to indoor air quality, and potentially, to the exposure of bystanders.

Generally, the existing data indicates that both EC and HTP usage results in lower adverse impact to indoor air compared to traditional cigarette, water pipe, as well as many other indoor pollution sources, such as incense burning and mosquito coils (Kaunelienè et al., 2018). Among gaseous pollutants, nicotine and acetaldehyde are among the most commonly associated with HTP usage (Mitova et al., 2016), while combustion byproducts $\mathrm{CO}, \mathrm{NO}$, and $\mathrm{NO}_{2}$ are not detected (Cozzani et al., 2020). 62 trace compounds were qualitatively identified in the exhaled HTP aerosol, including aldehydes, nitrogenated species, and aromatic species (Cancelada et al., 2019; Ilies et al., 2020).

Particulate matter is a group of pollutants frequently associated with the usage of thermal nicotine containing devices. The exhaled aerosol usually contains submicrometer/ultrafine (mostly liquid) particles, having mode at around $100 \mathrm{~nm}$. Due to a highly volatile nature, these particles are further subjected to transformations, such as nucleation, condensation, and evaporation. Moreover, particle aggregation and coagulation may occur since particle concentration during the exhalation exceeds $10 \mathrm{E}+6 \mathrm{~cm}^{-1}$. The prevailing mechanism depends on the type of aerosol generation device (EC vs. HTP) and environmental conditions, such as operating air conditioner (Loupa et al., 2019), distance of transport, and ventilation intensity (Meišutovič-Akhtarieva et al., 2019). The concentration levels of particle number concentrations following the usage of HTP vary broadly in the range from $1 \mathrm{E}+4$ to $1 \mathrm{E}+7 \mathrm{\#} \mathrm{cm}^{-3}$, while they directly depend on the proximity of the user to a bystander as well as the number of users, such as 10-30 (Ruprecht et al., 2017; Kaunelienè et al., 2019). Particulate matter mass concentrations were reported to vary between 14 to $21 \mu \mathrm{g} \mathrm{m}^{-3}$ during the exhalation of the HTP smoke (Protano et al., 2020).

The above presented summary of recent studies on the impacts of HTP and EC on indoor air quality indicate that while the usage of these devices results in a much lower deterioration of indoor air quality compared to traditional combustible tobacco products, the exhaled aerosol is a very dynamic system and is affected by multiple factors. Every new device or technology on a market should undergo a thorough investigation in well-controlled environment aiming at the accurate characterization of the generated aerosol and thus potential impacts to air quality and bystander exposure.

This study has researched an exhaled aerosol from the usage of a new HTP product and compared against a vaping product (EC) and a conventional cigarette (CC) in terms of highly time resolved particle concentrations and size distributions. Important factors affecting aerosol dynamics in a room were researched and quantitatively established.

\section{METHODS}

\subsection{Products}

The following nicotine containing products were investigated in the research: a heated tobacco product, Pulze, and an e-cigarette, myblu, both manufactured by Imperial Brands PLC (UK).

Pulze is a battery-powered heated tobacco device which heats up a refined tobacco rod 
(named $i D$ ) to a preset temperature-either $315^{\circ} \mathrm{C}$ in Eco mode (referred to as HTP_Eco in an experimental plan) or $345^{\circ} \mathrm{C}$ in Standard mode (HTP_Standard). Non-flavored iD sticks were used. The tobacco rod component of the iD stick consists primarily of reconstituted tobacco and glycerin (the principal humectant ingredient used for aerosol formation in the heated tobacco product). The aerosol is produced by heating and subsequent distillation process where active ingredients from tobacco are trapped in liquid mainstream aerosol, filtered within several stages of filtration within the iD stick and thus delivered to the user.

myblu is a battery-powered electronic cigarette device that heats liquid formulation to create an aerosol inhaled by the smoker. Such liquids can contain varying amounts of nicotine, which makes it different from HTP products, which contain naturally occurring nicotine in the tobacco leaf. Liquids additionally contain glycerin and propylene glycol as primary carriers of vaporized nicotine and may or may not contain flavorings.

The data on conventional cigarette has been taken from our earlier study comparing several types of ECs and the CC (Martuzevicius et al., 2019). This study was performed in the same setting using Marlboro Gold (Philip Morris International Inc.) having tar, nicotine, and carbon monoxide yields of $8 \mathrm{mg}, 0.6 \mathrm{mg}$, and $9 \mathrm{mg}$, respectively.

\subsection{Test Chamber}

An indoor test chamber representing a standard room was same as described by Martuzevicius et al. (2019) and schematically presented in Fig. S1 (Supplementary Material). Briefly, the chamber was built of conventional building materials (painted drywall walls, panel ceiling) and measured $13 \mathrm{~m}^{2}$ of floor area and $35.8 \mathrm{~m}^{3}$ of volume. A bystander (seated human being) represented by a dummy with a surface temperature of $34^{\circ} \mathrm{C}$ was positioned near a wall and was used as a sampling inlet. The chamber was equipped with an external air handling unit, providing a supply of air in the range from 0 to $12 \mathrm{~h}^{-1}$. The supply air was conditioned in a heat exchanger and treated by three steps of filtration-pre-filter of class F7, activated carbon bed (removing outdoor volatile organic compounds [VOCs] and ozone), and HEPA13 final filter. The four-way mixing ventilation was chosen for this study as it is commonly used in residential buildings. Such setup has been tested to provide sufficient dispersion of aerosol, generated in a room (Jurelionis et al., 2015). Relative humidity $(\mathrm{RH})$ has been controlled by humidifier (ES4; NORDMANN Engineering AG, Switzerland) in the range from $30 \%$ to $70 \%$, while the temperature was maintained within a range from $21^{\circ} \mathrm{C}$ to $23^{\circ} \mathrm{C}$.

\subsection{Measurement Methods}

Particle number concentration (PNC) and particle size distribution (PSD) was measured by the Fast Mobility Particle Sizer (FMPS) spectrometer (Model 3091; TSI Inc., USA) in the size range from 5.6 to $560 \mathrm{~nm}$ in 32 channels with $1 \mathrm{~s}^{-1}$ time resolution. The measured distributions were based on particle number concentration (unit particles $\mathrm{cm}^{-3}$ ) measurement. Before the start of each run a background concentration of particulate matter was recorded ( 3 min before the start). The background concentration at the beginning of each experiment was aimed to be achieved as low as possible, and ranged between 300 and 5000 particles $\mathrm{cm}^{-3}$.

Relative humidity and temperature were measured continuously (IAQ-Calc 7545; TSI Inc., USA) at a resolution of $30 \mathrm{~s}$. The same instrument was used for the verification of ventilation rate regimes based on the decay of $\mathrm{CO}_{2}$ concentration.

\subsection{Experiment Plan and Data Analysis}

The experiment has been designed as a full-factorial multiple linear regression interaction model, aided by an experiment planning software (MODDE 10.1; Umetrics Inc., Sweden). Full experimental worksheet is presented in Table S1 (Supplementary Material). The experiment factors (controlled variables) were set to Product Type (qualitative variable, having values of HTP_ECO, HTP_Standard, and EC), Ventilation Rate $\left(0.2 \mathrm{~h}^{-1}\right.$ representing minimum ventilation and $1 \mathrm{~h}^{-1}$ representing an intense ventilation regime), Relative Humidity (30\%, representing dry air, and $70 \%$, representing humid air) and Distance from a user to the dummy $(0.5,1.0$, and $2.0 \mathrm{~m})$. Additionally, three male volunteers (aged between 20 to 30 years) have been included to the study to represent the user variable (marked as V1, V2, and V3). Such design resulted in 108 total runs. No specific requirements were set to the volunteers participating in the study, except that 
they were a regular smoker or/and experienced e-cigarette user. Three male volunteers within 2030 years of age have signed for the study, acknowledging their consent to participate in a written form. The volunteers were regular smokers of traditional cigarettes and electronic cigarettes, but have not used the particular HTP product. No other user-related data has been collected, thus treating volunteers as an independent variable that brings random variation to the results.

The responses to the model that were derived from the real-time particle number concentration and size distribution measurements are presented in Table 1. All responses (except ratios) have been log-transformed in order to correct for skewness in distribution. The model data was fitted into multiple linear regression interaction model. After initial runs the insignificant (interaction mostly) terms were manually removed aiming to balance the goodness of the model based on the estimate of model fit $\left(R^{2}\right)$ and the estimate of the future prediction precision $\left(Q^{2}\right)$.

The experimental flow was conducted accordingly: The test chamber was purged before an experiment for at least $10 \mathrm{~min}$ at a ventilation rate of $10 \mathrm{~h}^{-1}$ to reduce the background concentration of particles. A volunteer entered the chamber and used HTP or vaped the EC according to planned regime, which was one puff every $30 \mathrm{~s}$, total of five puffs. Each volunteer used separate devices (three Pulze and myblu devices in total), while the HTP device has been loaded with a fresh rod before every experiment. After puffing, a tobacco rod has been extinguished in a flask filled with water to prevent any further aerosolization of particles. A volunteer remained calmly seated for additional $30 \mathrm{~min}$, and exited the chamber afterwards.

Table 1. Parameters derived from the real-time measurements of particle size-resolved number concentrations.

\begin{tabular}{|c|c|c|c|}
\hline Response name & Abbreviation & Units & Description \\
\hline \multicolumn{4}{|l|}{ Temporal variation parameters } \\
\hline $\begin{array}{l}\text { Maximum total particle } \\
\text { number concentration } \\
\text { (PNC) }\end{array}$ & $\mathrm{PNC}_{\mathrm{t}, \max }$ & $\# \mathrm{~cm}^{-3}$ & $\begin{array}{l}\text { The highest PNC obtained during a single run. This } \\
\text { indicates the level of total PNC immediately } \\
\text { following the exhalation. }\end{array}$ \\
\hline Total PNC after $5 \mathrm{~s}$ & $\mathrm{PNC}_{\mathrm{t}, 5 \mathrm{~s}}$ & $\# \mathrm{~cm}^{-3}$ & $\begin{array}{l}\text { PNC following the last peak after } 5 \mathrm{~s} \text {. Indicates the } \\
\text { rapid dispersion/transformation of particles. }\end{array}$ \\
\hline Total PNC after $10 \mathrm{~s}$ & $\mathrm{PNC}_{\mathrm{t}, 10 \mathrm{~s}}$ & $\# \mathrm{~cm}^{-3}$ & $\begin{array}{l}\text { PNC following the last peak after } 10 \mathrm{~s} \text {. Indicates the } \\
\text { rapid dispersion/transformation of particles. }\end{array}$ \\
\hline Total PNC after $120 \mathrm{~s}$ & $\mathrm{PNC}_{\mathrm{t}, 120 \mathrm{~s}}$ & $\# \mathrm{~cm}^{-3}$ & $\begin{array}{l}\text { PNC following the last peak after } 120 \mathrm{~s} \text {. Indicates } \\
\text { the long-term processes of particle } \\
\text { transformations. }\end{array}$ \\
\hline $\begin{array}{l}\text { Concentration ratio: PNC } \\
\text { after } 5 \mathrm{~s} / \mathrm{PNC}_{\max }\end{array}$ & $\mathrm{PNC}_{\mathrm{t}, 5 \mathrm{~s}} / \mathrm{PNC}_{\mathrm{t}, \max }$ & Non-dimensional & $\begin{array}{l}\text { Indicates the decrease of PNC after } 5 \mathrm{~s} \text { from the } \\
\text { maximum, in relation to the maximum. }\end{array}$ \\
\hline $\begin{array}{l}\text { Concentration ratio: PNC } \\
\text { after } 10 \mathrm{~s} / \mathrm{PNC}_{\max }\end{array}$ & 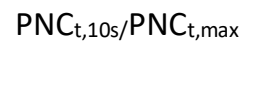 & Non-dimensional & $\begin{array}{l}\text { Indicates the decrease of PNC after } 10 \mathrm{~s} \text { from the } \\
\text { maximum, in relation to the maximum. }\end{array}$ \\
\hline $\begin{array}{l}\text { Concentration ratio: PNC } \\
\text { after } 120 \mathrm{~s} / \mathrm{PNC}_{\max }\end{array}$ & 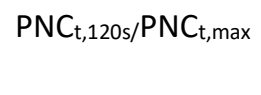 & Non-dimensional & $\begin{array}{l}\text { Indicates the decrease of PNC after } 120 \mathrm{~s} \text { from the } \\
\text { maximum, in relation to the maximum. }\end{array}$ \\
\hline $\begin{array}{l}\text { Concentration decrease rate } \\
\text { from } \mathrm{PNC}_{\max } \text { to } \mathrm{PNC}_{5 \mathrm{~s}}\end{array}$ & $r_{\max -5}$ & $\min ^{-1}$ & $\begin{array}{l}\text { Indicates the rate of the PNC decrease, following } \\
\text { the exponential decay kinetics, and calculated as } \\
\left(\operatorname{lnPNC} C_{t, \max }-\ln P N C_{t, 5 s}\right) /(5 / 60) \text {. }\end{array}$ \\
\hline $\begin{array}{l}\text { Concentration decrease rate } \\
\text { from } \mathrm{PNC}_{\max } \text { to } P N C_{t, 10 s}\end{array}$ & $r_{\text {max }-10}$ & $\min ^{-1}$ & $\begin{array}{l}\text { Indicates the rate of the PNC decrease, following } \\
\text { the exponential decay kinetics, and calculated as } \\
\left(\operatorname{lnPNC} C_{t, \max }-\ln P N C_{t, 10 s}\right) /(10 / 60) \text {. }\end{array}$ \\
\hline \multicolumn{4}{|l|}{ Particle size distribution parameters } \\
\hline Mode at maximum peak & $M_{\max }$ & $\mathrm{nm}$ & $\begin{array}{l}\text { Particle size having the highest concentration } \\
\text { during } \mathrm{PNC}_{\mathrm{t}, \max \text {. }}\end{array}$ \\
\hline Mode after $5 \mathrm{~s}$ & $M_{5 s}$ & $\mathrm{~nm}$ & $\begin{array}{l}\text { Particle size having the highest concentration } \\
\text { during } P N C_{t, 5 s} \text {. }\end{array}$ \\
\hline Mode after $10 \mathrm{~s}$ & $\mathrm{M}_{10 \mathrm{~s}}$ & $\mathrm{~nm}$ & $\begin{array}{l}\text { Particle size having the highest concentration } \\
\text { during } \mathrm{PNC}_{\mathrm{t}, 10 \mathrm{~s}}\end{array}$ \\
\hline Mode after $120 \mathrm{~s}$ & $\mathrm{M}_{120 \mathrm{~s}}$ & $\mathrm{~nm}$ & $\begin{array}{l}\text { Particle size having the highest concentration } \\
\text { during } P N C_{t, 120 s} \text {. }\end{array}$ \\
\hline
\end{tabular}




\section{RESULTS AND DISCUSSION}

\subsection{Temporal Variations of Particle Number Concentrations during and after the Product Usage}

The usage of tobacco products in an enclosed environment usually results in a very characteristic variation of particle concentration, which may be characterized by a sharp increase of PNC following the exhalation of inhaled mainstream aerosol, and then an equally sharp decrease in concentration to almost background, as quantitatively presented lower in this subchapter. Such pattern of temporal variability is valid in case of both conventional cigarette, as well as electronic or heated tobacco products (Martuzevicius et al., 2019; Meišutovič-Akhtarieva et al., 2019). Depending mostly on the distance from a user to the bystander, the sharpness of the peaks may be more or less pronounced.

We have observed an expected variation of PNC at a bystander's position, with clearly identifiable five peaks at a close proximity $(0.5 \mathrm{~m}$; Fig. 1$)$. The PNC variations of all devices and regimes are presented in same scale in Fig. 1 deliberately to reflect the magnitude of variations. In case a user is close to a bystander, the puff does not have sufficient time to disperse in the volume of the chamber. At further distances, the exhaled puffs can still be registered, but the level of concentration is much lower, and the peaks are not as sharp.

At a close proximity, EC produced higher number of particles, compared to HTP operating in both Eco and Standard mode. Across all runs, the HTP in Eco regime resulted in $\mathrm{PNC}_{\mathrm{t}, \mathrm{max}}$ at $0.5 \mathrm{~m}$ distance averaged at $1.14 \mathrm{E}+06 \pm 3.91 \mathrm{E}+05 \# \mathrm{~cm}^{-3}, \mathrm{HTP}$ in Standard mode $1.66 \mathrm{E}+06 \pm 4.89 \mathrm{E}+05 \mathrm{~cm}^{-3}$, while $\mathrm{EC}$ resulted in $4.26 \mathrm{E}+06 \pm 1.05 \mathrm{E}+06 \# \mathrm{~cm}^{-3}$, i.e., 2.6 and 3.7 times higher from HTP, which is a statistically significant difference $(p<0.05)$. Similar trend holds for the distances of 1 and $2 \mathrm{~m}$, with PNC $\mathrm{C}_{\text {,max }}$ generated by EC was 4.0-5.0 and 1.0-8.2 times higher than HTP, respectively. Such difference is determined by a more efficient aerosol generation within the electronic cigarette, which results in a higher mainstream aerosol concentration, $10 \mathrm{E}+9 \# \mathrm{~cm}^{-3}$ for $\mathrm{EC}$ (Belka et al., 2017)

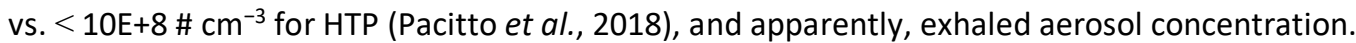

HTP operating regime (Eco vs. Standard) did not yield significant differences in terms of the temporal variation of exhaled aerosol particles and the concentration levels, and was within a $95 \%$ confidence interval in all distances as averaged across all regimes. This may be due to the fact that other environmental factors play a more important role in aerosol variation. Generally, a different temperature of heating may be expected to result in a substantially different mainstream aerosol generated by a device but these differences are reduced once the aerosol is transformed within human respiratory system. In several cases, such as at a closest proximity to a bystander, a significant difference between product regimes emerged in terms of the indexes representing the exhalation moment $\left(\mathrm{PNC}_{\mathrm{t}, \mathrm{max}}, \mathrm{PNC}_{\mathrm{t}, \mathrm{s}}\right)$ at a higher ventilation rate $\left(1 \mathrm{~h}^{-1}\right)$. This shows that the Standard regime may result in a higher aerosol concentration immediately after the exhalation.

The obtained concentration variation pattern and levels during exhaled puff in this study are comparable to those obtained during our earlier studies with similar/other devices. For example, the vaping of Puritane (an early-generation electronic cigarette device) resulted in peak concentrations from $1.2 \mathrm{E}+06$ to $2.8 \mathrm{E}+06 \mathrm{~cm}^{-3}$ at $0.5 \mathrm{~m}$ distance (Martuzevicius et al., 2019), while using Tobacco Heating System IQOS yielded average of $0.5 \mathrm{E}+06$ to $1.6 \mathrm{E}+06 \mathrm{\#} \mathrm{cm}^{-3}$, reaching $9.3 \mathrm{E}+06 \mathrm{~cm}^{-3}$ (Meišutovič-Akhtarieva et al., 2019). Conventional cigarette has resulted in a broader range of peak concentrations, ranging from $1.27 \mathrm{E}+06$ to $2.615 \mathrm{E}+08 \mathrm{\#} \mathrm{cm}^{-3}$ at $0.5 \mathrm{~m}$ distance (Martuzevicius et al., 2019).

The peak concentration $\left(\mathrm{PNC}_{t, \text { max }}\right)$ is an important estimate of short-term exposure to particulate matter during the usage of either EC or HTP. However, these peaks are very short-lived (up to $5 \mathrm{~s}$ ), and it is important to define parameters which reflect the aerosol behavior after/between peaks. The particles generated during the vaping of ECs (as opposed to those of conventional cigarettes) have a very volatile composition, namely, consisting of mostly water and propylene glycol/glycerol vapor, thus not only disperse quickly in a room, but also evaporate (Bertholon et al., 2013; Zhao et al., 2017; Pacitto et al., 2018; Meišutovič-Akhtarieva et al., 2019). We have hypothesized that after the last puff, the total PNC (PNCt) should remain at the background level and not increase once the room volume is filled with exhaled particles while the ventilation is not capable in removing those during the period of $2 \mathrm{~min}$. 

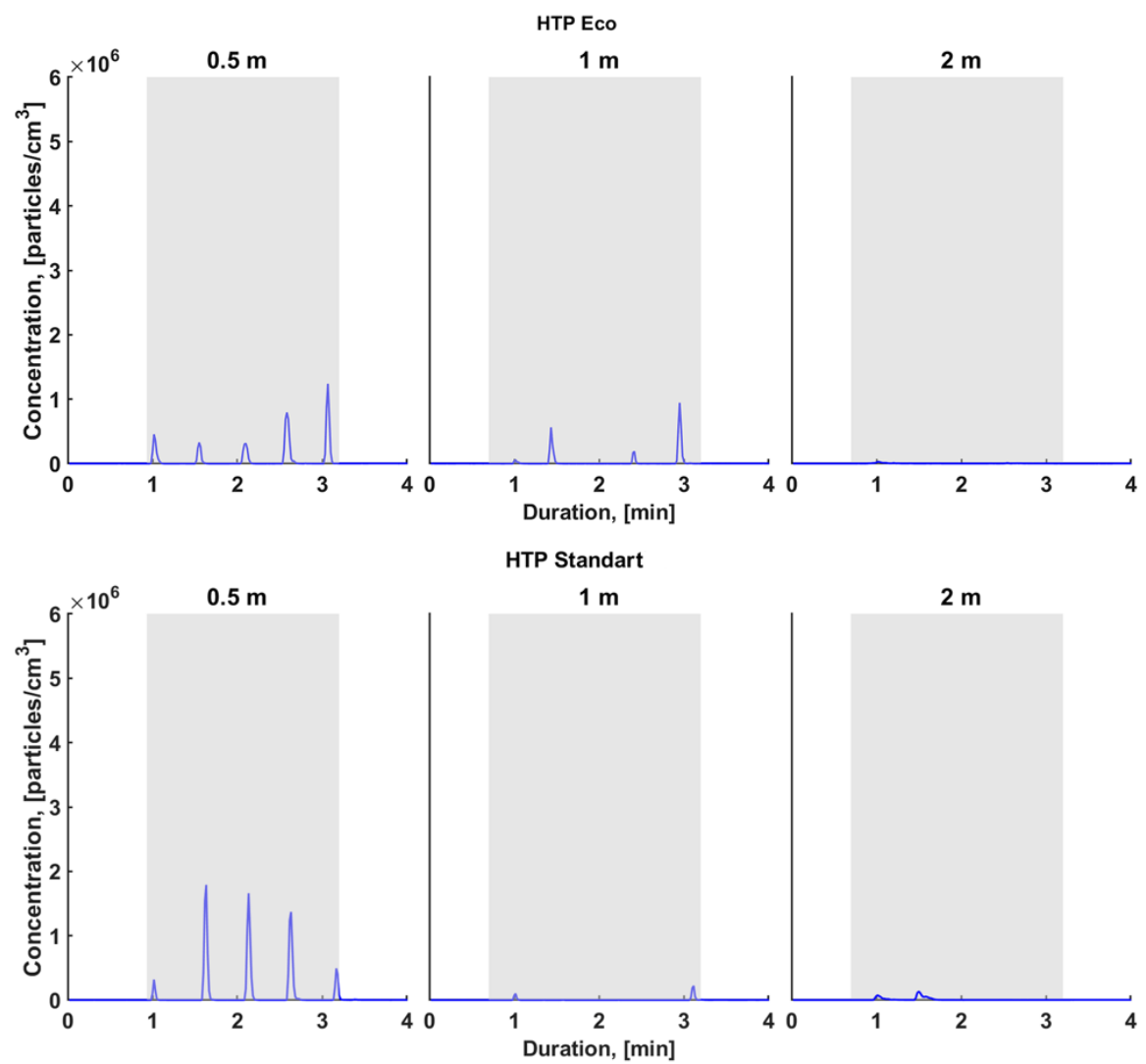

EC

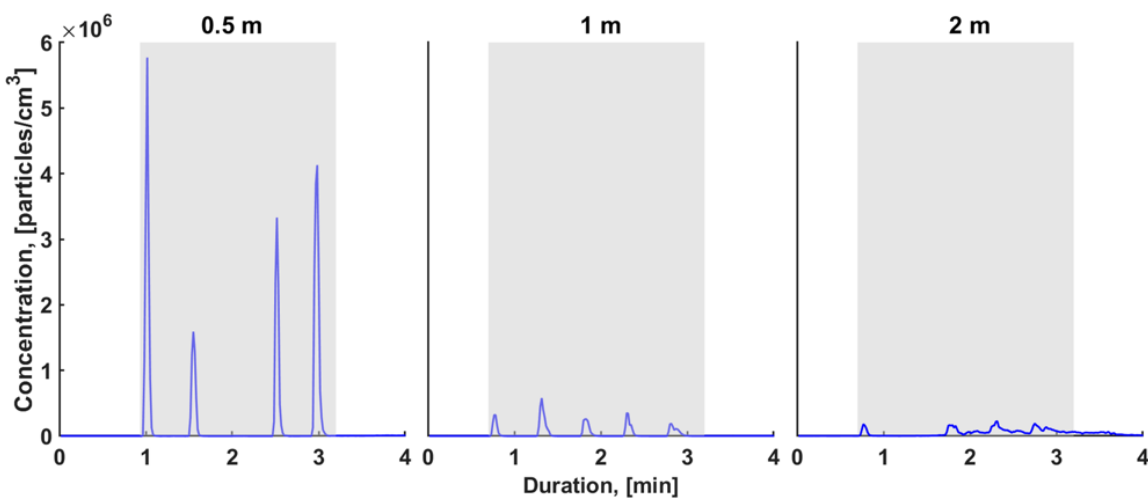

CC
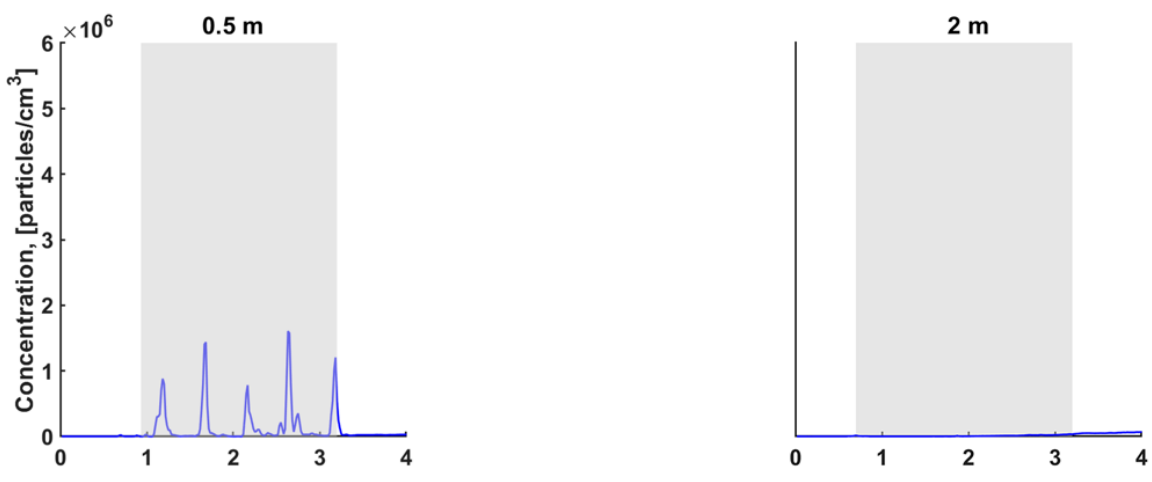

Fig. 1. Temporal variation of total particle number concentration following the usage of the tested HTP, EC, and CC (the latter data presented from Martuzevicius et al., 2019) products at various distances of the user to the bystander, at the following environmental conditions: ventilation intensity $1 \mathrm{~h}^{-1}$, relative humidity $(\mathrm{RH}) 30 \%$. 


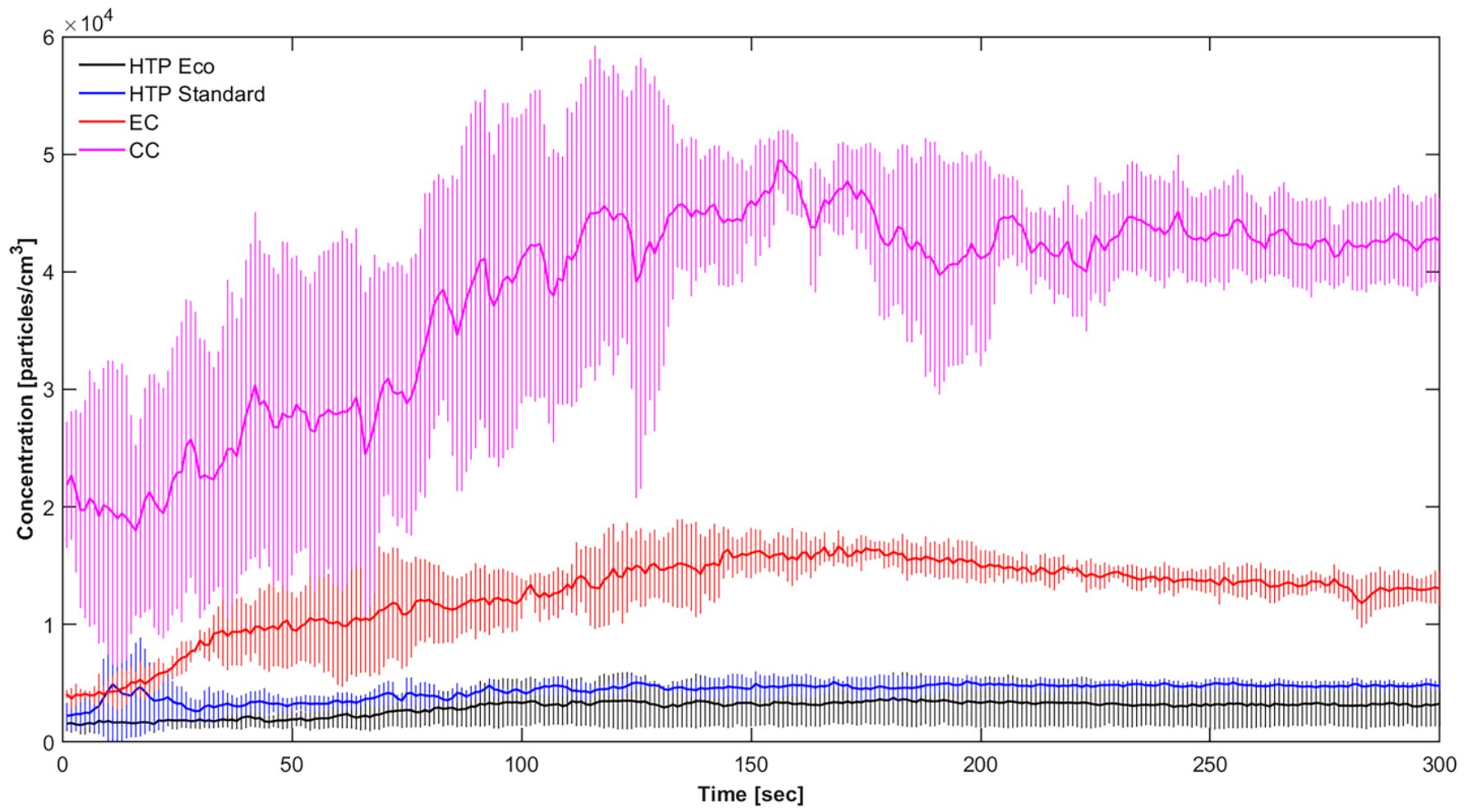

Fig. 2. Temporal variation of PNC at the bystander position starting at $20 \mathrm{~s}$ after the usage of HTP, EC (the average of three volunteers), and CC (the latter data presented from Martuzevicius et al., 2019). Distance between the vaper and the bystander $=0.5 \mathrm{~m}$, ventilation intensity $=1 \mathrm{~h}^{-1}$, relative humidity $=30 \%$.

The characteristic behavior of $\mathrm{PNC}_{t}$ following the last puff is presented in Fig. 2. Once dropping to $10 \mathrm{E}+3 \mathrm{\#} \mathrm{cm}^{-3}$ level, it remains constant, such as in case of HTP, or slightly rises to $1 \mathrm{E}+4 \mathrm{\#} \mathrm{cm}^{-3}$ level, as in case of EC. Generally, EC resulted in higher $\mathrm{PNC}_{\mathrm{t}, 120 \mathrm{~s}}$ across all distances. This is somewhat unexpected, since the EC particles may have higher volatility due to being fully generated from liquid, while HTP are tobacco-derived and thus may have non-volatile core (due to a presence of aerosol fraction, referred to as nicotine-free dry particulate matter [NFDPM]; Bentley et al., 2020).

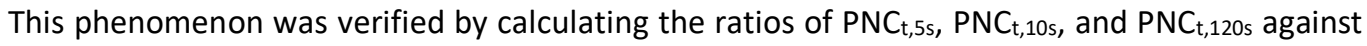
the peak $P N C_{t, m a x}$ thus normalizing the residual concentration in comparison to the maximum. Such comparison for each tested product is presented in Fig. 3(a) as factor plots. While the large variation among multiple runs and conditions resulted in statistically insignificant differences, the averaged values indicate that EC actually ends up in a lower concentration at both 5, 10, and $120 \mathrm{~s}$ after a puff peak, namely, the residual concentration in case of EC after $120 \mathrm{~s}$ comprises $\sim 0.5 \%$ of the PNC $\mathrm{C}_{\mathrm{t} \text { max, }}$ while in case of HTP this ratio is up to $1.5-2.5 \%$.

Additionally, we have calculated the concentration decrease (decay) rate following the peak during first 5 and $10 \mathrm{~s}$ (Fig. 3(b)). Again, the EC resulted in a more rapid concentration decay (41.2 $\pm 9.3 \mathrm{~min}^{-1}$ after $5 \mathrm{~s}$ and $29.7 \pm 4.7 \mathrm{~min}^{-1}$ after $10 \mathrm{~s}$ ). This confirms that while the peak concentration of EC is higher than HTP, the particle removal/decay is also faster, owing to a higher volatility of particles (droplets).

It must be emphasized that the processes following the exhalation of highly concentrated aerosol are very complex and go beyond only evaporation. The aerosol removal mechanisms include discharge with ventilation air and gravitational settling. At the same time, particle aggregation (conjugation of similarly sized particles) and coagulation (sticking to larger droplets) may occur. Furthermore, not only particle removal, but formation may take place, such as secondary organic aerosol, considering a relatively high emission of volatile organic species. We do not anticipate strong contribution of the latter mechanism in chamber environment due to low concentration of ozone in supply air and lack of UV radiation, but these processes may be more pronounced in real-world indoor environments. 
(a)

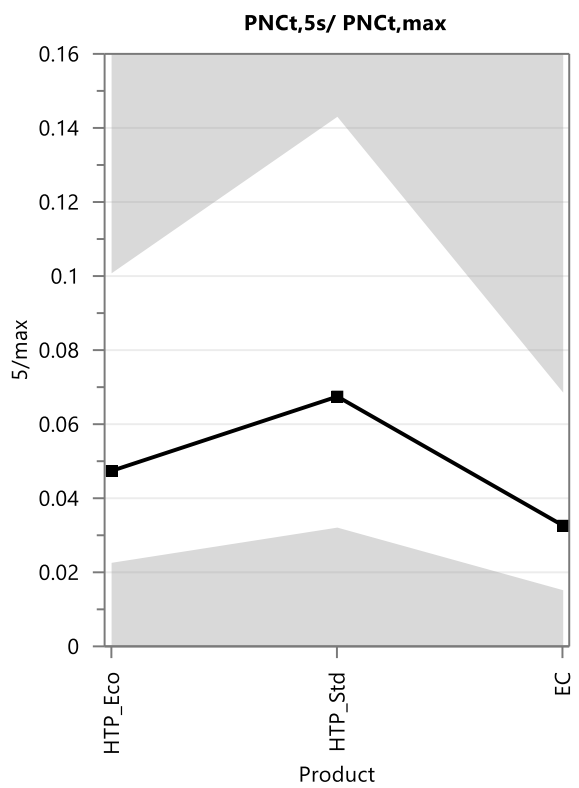

(b)

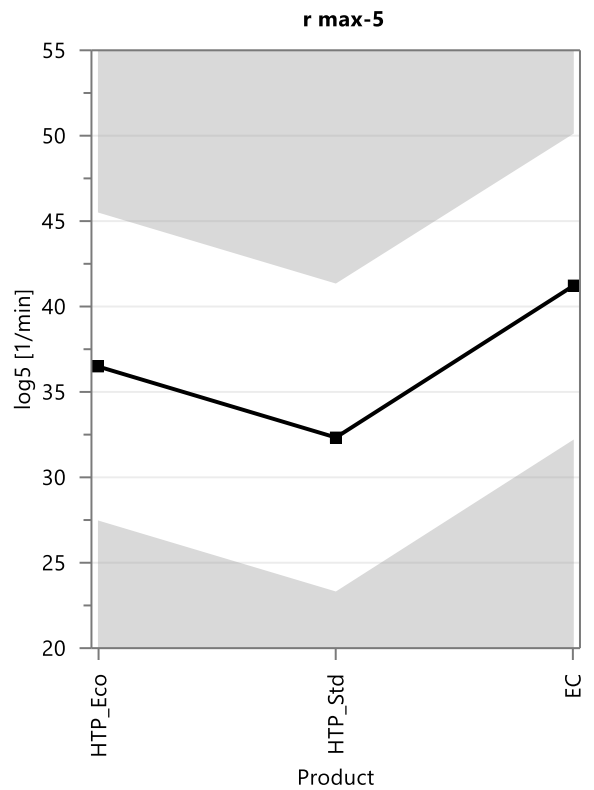

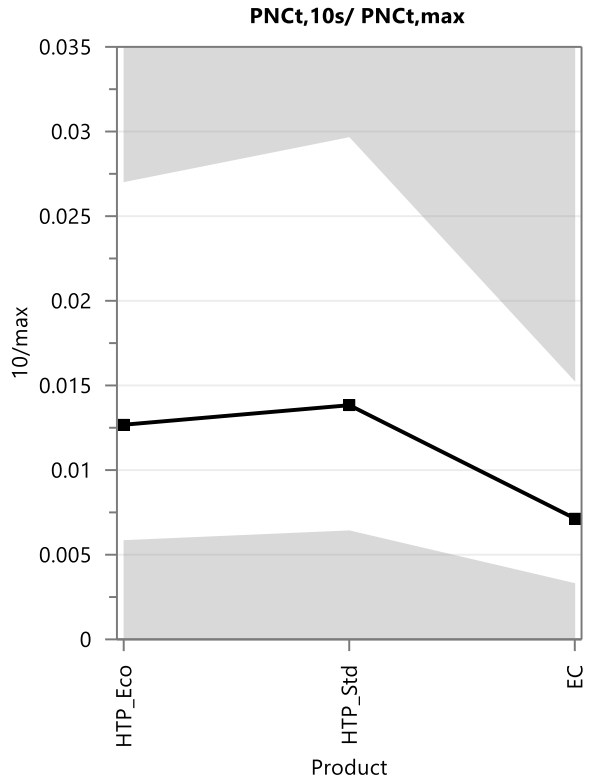
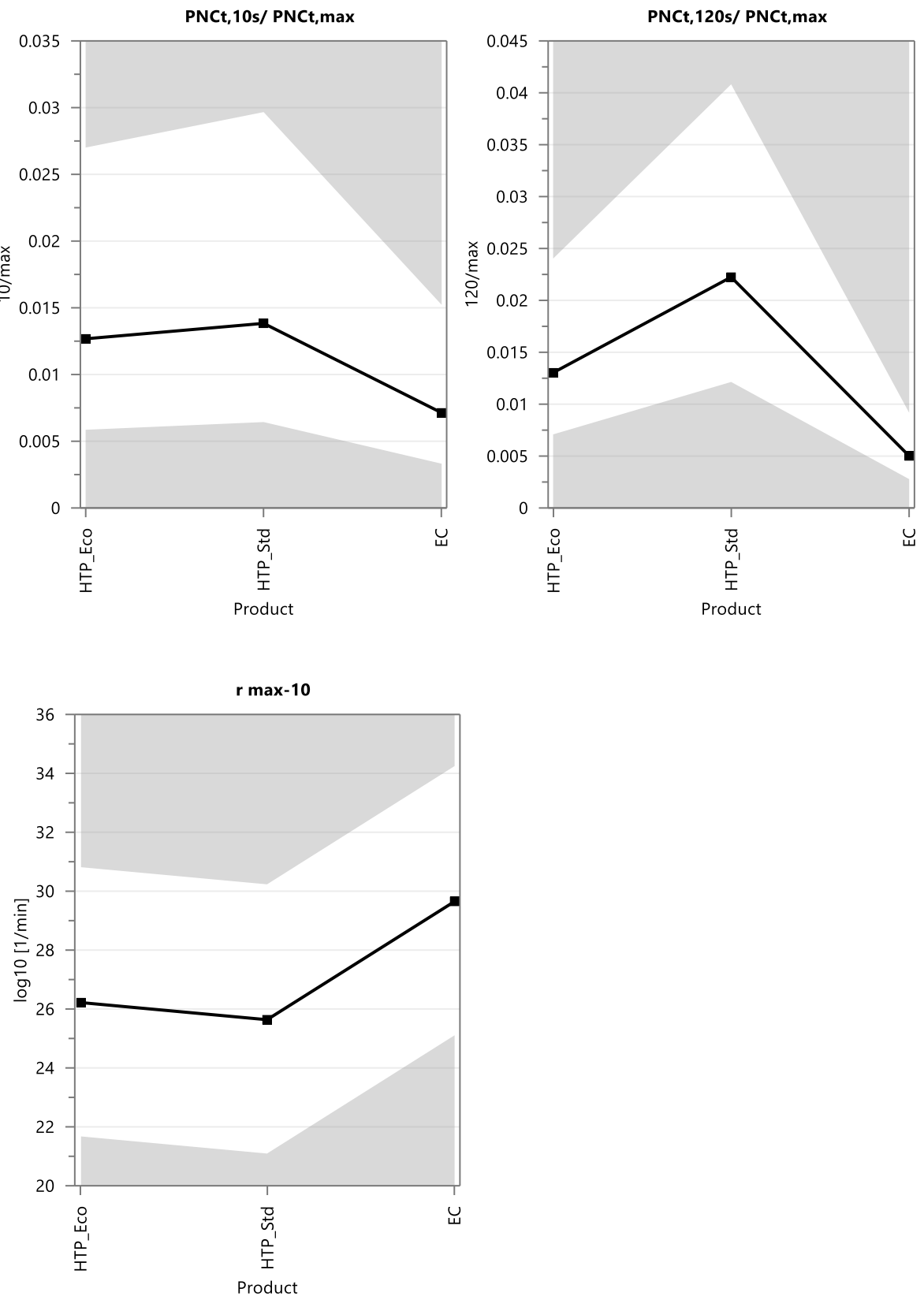

Fig. 3. Temporal variation of PNC following exhalation after usage of tested products: (a) concentration after 5,10 and $120 \mathrm{~s}$ in relation to maximum; (b) concentration decrease rate from maximum to 5 and $10 \mathrm{~s}$.

\subsection{Particle Size Distributions}

Particle size distribution is a very important parameter in case of experimenting with highly dynamic sources of potential air pollution, such as vaping or using heated tobacco products. The particles generated during the vaping of electronic cigarettes (as opposed to those of conventional cigarettes) have a very volatile composition, namely, consisting of mostly water, propane-1,2diol (propylene glycol), and propane-1,2,3-triol (glycerol) vapor, thus not only disperse quickly in a room, but also evaporate. This results in rapid variations of not only total concentrations of particles, but also in types of distributions. The mainstream aerosol generated by such devices has been reported as having trimodal with a primary mode at $250 \mathrm{~nm}$ and two secondary modes at approximately 30-80 nm and $1 \mu \mathrm{m}$ (Li et al., 2020). In exhaled aerosol PSD, the mode shifts towards $100 \mathrm{~nm}$ (Pacitto et al., 2018; Palmisani et al., 2019). At the same time, rapid evaporation of these volatile particles results in the appearance of a nucleation mode at 2-10 nm, which 
indicates the transition of aerosol particles to gas phase (Mikheev et al., 2016). The shift from accumulation mode to nucleation mode of exhaled aerosol may be observed during highly time resolved measurements in case of both the electronic cigarette (Martuzevicius et al., 2019), and the heated tobacco product (Meišutovič-Akhtarieva et al., 2019).

Throughout the study we have observed a broad variety of PSDs. A bimodal distribution was prevalent for both devices, with the main mode usually located at approximately $60-80 \mathrm{~nm}$ for HTP and $115 \mathrm{~nm}$ for EC during the puff. At the same time, a secondary mode was also apparent at a first channel of FMPS, however, most of the time much lower. There was also a substantial variation in PSD shape and mode allocations among various time periods, distances to bystander, as well as among volunteers. Interestingly, the PSD changed many times among puffs by the same volunteer, indicating that the transformations of an inhaled mainstream aerosol may compose an important factor worth exploring further.

Fig. 4 presents a case of PSD at a close distance to a bystander during the puff, and 5, 10, and $120 \mathrm{~s}$ after the last puff (average and standard deviation among five puffs and three volunteers). The variation among volunteers was rather high and reflected by broad intervals of two standard deviations. This is especially noticeable in the case of the HTP operating in Standard mode, where lower bound of error bar reached zero and could not be displayed in logarithmic axis in case of 5 and $10 \mathrm{~s}$ after a puff. The distributions of this case emerged as bimodal during the puff. The main mode was $93 \mathrm{~nm}$ for HTP in both Eco and Standard regimes, and $123 \mathrm{~nm}$ for EC. The latter also represented higher concentration of particles compared to HTP. Another mode was evident for all devices at $6 \mathrm{~nm}$. After $5 \mathrm{~s}$ from the puff the concentration got reduced by several orders of magnitude, while main modes have shifted towards smaller particle sizes ( $52 \mathrm{~nm}$ in Eco, $81 \mathrm{~nm}$ in Standard, $107 \mathrm{~nm}$ for EC). $10 \mathrm{~s}$ after a puff the main mode further shifts to smaller particle size, while the amount of larger particles $(400-500 \mathrm{~nm}$ ) dropped to almost zero. The relative amount of smallest particles also decreased, compared to the peak or $5 \mathrm{~s}$ after.

The above presented PSD patterns for HTP and EC devices were different from conventional cigarette in the following aspects: a) The accumulation mode of PNC during puff was larger for CC (165-200 nm as opposed to $93 \mathrm{~nm}$ for HTP and $123 \mathrm{~nm}$ for EC); b) this mode has barely shifted
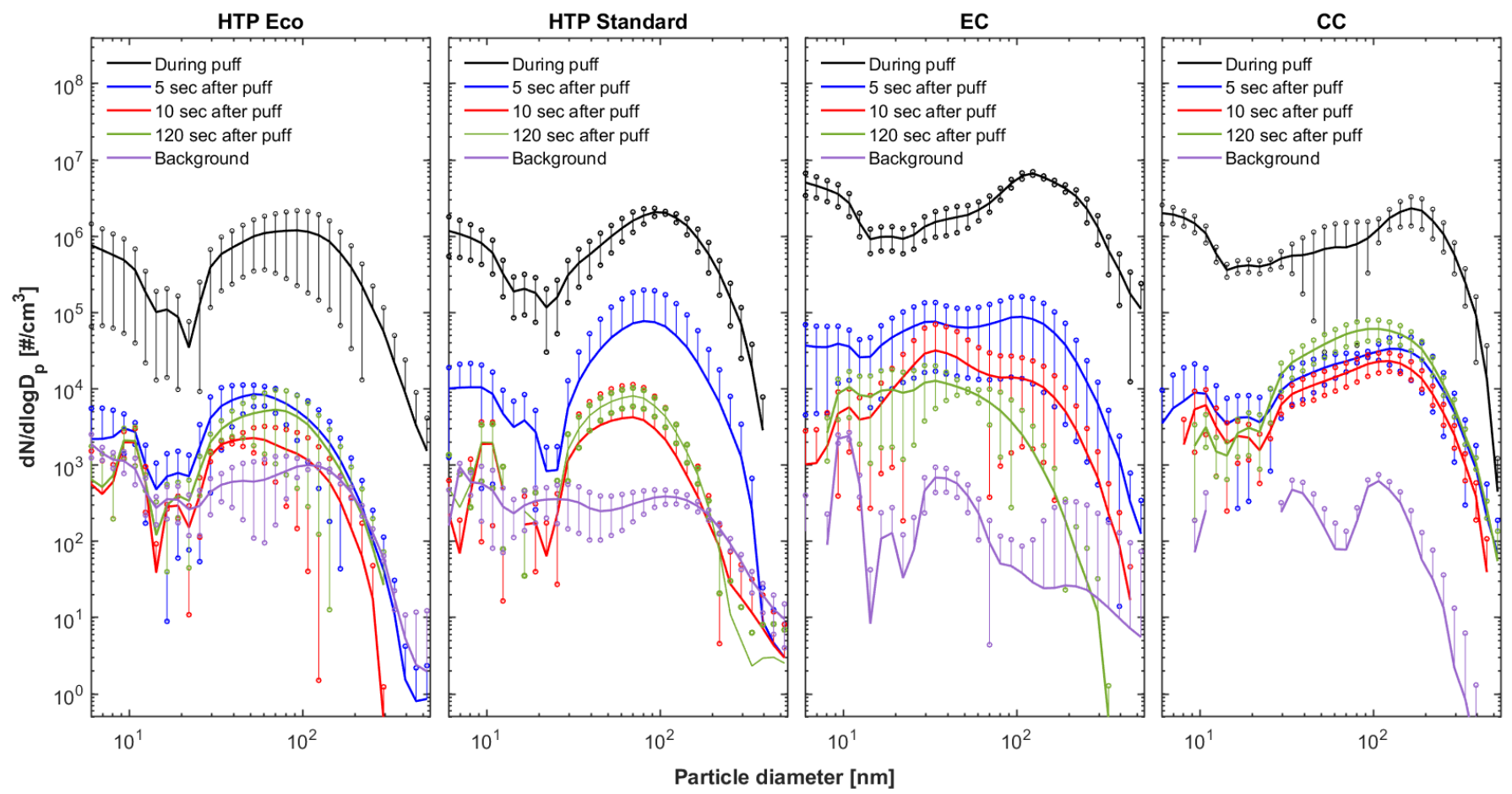

Fig. 4. Characteristic particle size distributions (PSDs) of ambient aerosol following the exhalation/puff after usage of tested HTP, EC and CC (the latter data presented from Martuzevicius et al., 2019) during puff, and 5, 10, $120 \mathrm{~s}$ after puff. Distance between the vaper and the bystander $=0.5 \mathrm{~m}$, ventilation intensity $=1 \mathrm{~h}^{-1}$, relative humidity $=30 \%$. An average and standard deviation of the three volunteers is presented. 
to a smaller size range with a time, $100-200 \mathrm{~nm}$ range as compared to the reduced modes (52$81 \mathrm{~nm}$ for HTP, $107 \mathrm{~nm}$ for EC). This confirms that the composition and thus volatility of exhaled aerosol particles is significantly different in case of HTP and EC as opposed to CC.

The phenomenon of volatile particle transformations after exhalation is yet to be researched systematically. It is obvious that the transformation of exhaled particle follows a different mechanism as opposed to the inhaled mainstream aerosol. The mainstream aerosol of HTP has been estimated to contain $75-85 \%$ of water (Uchiyama et al., 2018), while EC contains $73-83 \%$ glycerin (Long, 2014). This is much different from traditional cigarette mainstream emissions which only contain $17-27 \%$ of water.

The high-temperature mainstream aerosol particles first cool, then hygroscopically grow in size during the inhalation in water-saturated respiratory airways. In such environment, CC particle growth is slower compared to EC (Feng et al., 2015), and presumably, to HTP. The particles cooled and enlarged particles which do not get adsorbed on airway tissue start shrinking in size already in airways and then continue evaporating in a relatively dry indoor air (compared to airway environment). Thus, we observe very fast evaporation of EC and HTP particles, which were indicated to have half-life of $11 \mathrm{~s}$ (for EC), as opposed to 19-20 min of CC (Bertholon et al., 2013). While CC particles lose a relatively small amount of adsorbed water leaving a low-volatility core of primary particles, the EC and HTP particles lose both adsorbed water and volatile constituents; thus, the observed evaporation is much faster and shorter.

\subsection{Factors Affecting the Dynamics of Aerosol}

The presented data in this manuscript has been obtained from full-factorial experimental design, allowing the assessment of statistical significance of the process factors. The data presented in the above sections have already indicated some trends that were quantitatively confirmed by the model. Generally, the model suffered from relatively low statistical power $\left(R^{2}\right.$ ranging from $0.07 \mathrm{M}_{5 s}$ to 0.64 for $\mathrm{PNC}_{t, \mathrm{max}}$ ), yet statistically significant, based on $\mathrm{Q}^{2}$ value. Such outcome was partially unexpected, since the experiments have been performed under strictly controlled conditions. The largest uncertainty has been brought in with three volunteers, having different topographies for product usage.

The significant experimental variables are listed in Table 2. It is apparent that the exhaled aerosol from the two tested products-HTP and EC-have significant differences in terms of variation of particle concentration and diameter, depending on conditions. The effect of these variables was usually opposite, such as in case of PNC ${ }_{t, m a x}$, the HTP_Eco and HTP_Std coefficient values were

Table 2. Significant process variables. ${ }^{*}$ denotes statistically significant model term, $p<0.05$ (specific values are listed in parenthesis). 0 denotes terms having $p>0.05$.

\begin{tabular}{|c|c|c|c|c|c|c|}
\hline \multirow{2}{*}{ Response } & \multicolumn{6}{|c|}{ Experimental variables } \\
\hline & Product & Distance & Ventilation & $\mathrm{RH}$ & Volunteer & Interaction terms \\
\hline $\mathrm{PNC}_{\mathrm{t}, \max }$ & * & * & 0 & 0 & $*(\mathrm{~V} 1)$ & 0 \\
\hline $\mathrm{PNC}_{\mathrm{t}, 5 \mathrm{~s}}$ & $*$ & 0 & 0 & 0 & * (V3) & HTP_Eco*Vent, EC*Vent \\
\hline $\mathrm{PNC}_{\mathrm{t}, 10 \mathrm{~s}}$ & $*$ & $*$ & 0 & 0 & 0 & EC*Vent \\
\hline $\mathrm{PNC}_{\mathrm{t}, 120 \mathrm{~s}}$ & $*(\mathrm{HTP}$ ECO, EC) & 0 & 0 & 0 & $*(\mathrm{~V} 1)$ & 0 \\
\hline $\mathrm{PNC}_{\mathrm{t}, 5 \mathrm{~s}} / \mathrm{PNC}_{\mathrm{t}, \mathrm{max}}$ & $0-$ & * & 0 & 0 & 0 & EC*Vent \\
\hline $\mathrm{PNC}_{\mathrm{t}, 10 \mathrm{~s} /} / \mathrm{PNC}_{\mathrm{t}, \max }$ & 0 & * & 0 & 0 & 0 & 0 \\
\hline $\mathrm{PNC}_{\mathrm{t}, 120 \mathrm{~s}} / \mathrm{PNC}_{\mathrm{t}, \max }$ & * (HTP_Std, EC) & $*$ & 0 & 0 & $*(\mathrm{~V} 1, \mathrm{~V} 3)$ & EC*Dist \\
\hline$r_{\text {max }-5}$ & 0 & $*$ & 0 & 0 & & EC*Vent \\
\hline$r_{\max -10}$ & 0 & * & 0 & 0 & 0 & 0 \\
\hline $\mathrm{PNC}_{6 \mathrm{~nm}, 5 \mathrm{~s}}$ & $*(\mathrm{HTP}$ ECCO, EC) & $*$ & 0 & 0 & $*(\mathrm{~V} 1)$ & HTP_Eco*V1 \\
\hline $\mathrm{PNC}_{6 \mathrm{~nm}, 10 \mathrm{~s}}$ & $*(\mathrm{EC})$ & 0 & 0 & 0 & $*(\mathrm{~V} 1, \mathrm{~V} 3)$ & 0 \\
\hline $\mathrm{PNC}_{6 \mathrm{~nm}, 120 \mathrm{~s}}$ & 0 & 0 & 0 & 0 & $*$ & HTP_Eco*V2 \\
\hline$M_{\max }$ & * (HTP Std, EC) & * & 0 & 0 & 0 & HTP Std*Dist \\
\hline$M_{5 s}$ & $0-$ & 0 & 0 & 0 & 0 & 0 \\
\hline $\mathrm{M}_{10 \mathrm{~s}}$ & 0 & $*$ & 0 & 0 & $*(\mathrm{~V} 1, \mathrm{~V} 3)$ & EC*V3 \\
\hline$M_{120 s}$ & * & 0 & 0 & 0 & 0 & Dist*RH \\
\hline
\end{tabular}


negative, while EC's were positive, indicating that the latter contributed to larger values of PNC. In case of $\mathrm{M}_{120 \mathrm{~s}}$, this trend was opposite and HTP resulted in positive coefficients, while EC in negative. This agrees well with the observations in the above sections, where we presented data to show that EC results in higher PNC, but the particle shrinkage is also faster; however, the decay rate $(r)$ was not significant for various products. Although these products can be distinguished statistically in a controlled experiment under chamber conditions, real-world environment may be more challenging, if at all possible.

The distance from a bystander is another important parameter affecting both potential exposure level and the particle size. This is especially evident in case of puff (peak concentration) or immediately afterwards. After $120 \mathrm{~s}$ the distance has less effect due to a substantial time of aerosol travel and dispersion within the room; thus, the transformation processes managed to reach more or less stationary conditions.

Ventilation intensity and relative humidity did not yield significant contributions to the model, thus rejecting our hypotheses about their importance. The limited impact of ventilation has been demonstrated in our earlier chamber studies researching EC and HTP products (Martuzevicius et al., 2019; Meišutovič-Akhtarieva et al., 2019). This is due to the fact that the source intensity of exhaled aerosol and the transformations of aerosol are substantially faster and overwhelming processes, compared to a relatively slow process of air replacement at up to 1 changes per hour. The effects of $\mathrm{RH}$ on particle condensation/evaporation processes are important (Feng et al., 2015; Martuzevicius et al., 2019), but apparently, again, the rapidness of particle dispersion and transformations overshadows potential impacts of $\mathrm{RH}$. A significant positive effect of $\mathrm{RH}$ has been registered when considering mode of particles after $120 \mathrm{~s}$, in interaction with the distance. Possibly, this timespan was sufficient to observe the impact of $\mathrm{RH}$ to condensation of ambient water vapor particle size growth after exhalation.

The effect of volunteer, i.e., the topography of usage, is the most ambiguous factor in this experiment. Only Volunteers 1 or 3 have been associated with significant effect to the particle variation. Moreover, this effect has been an opposite-whenever both V1 and V3 were significant, $\mathrm{V} 1$ was positive and $\mathrm{V} 3$ was negative (such as in $\mathrm{PNC}_{6 \mathrm{~nm}, 10 \mathrm{~s}}, \mathrm{M}_{10 \mathrm{~s}}$ ), or vice versa $\left(\mathrm{PNC}_{\mathrm{t}, 120 \mathrm{~s}} / \mathrm{PNC}_{\mathrm{t}, \mathrm{max}}\right.$ ). It is difficult to interpret such findings based on the actual processes during the usage. While the volunteers have been instructed about the purpose of the experiment and were given general instructions about the product usage regime, it seems that a large variation occurred during the course of experiment, thus obstructing not only clear effect of volunteer to the process, but bringing in much variation in entire dataset and diminishing associations that would allow establishing stronger models. At the same time, this illustrates the fact that the usage of HTP or EC may be largely subjected to the usage topography, and the variation among users may hinder underlying differences between products.

Several plots as predicted from the model, depicting main quantitative associations between aerosol parameters, such as $\mathrm{PNC}_{t, \max }, \mathrm{PNC}_{\mathrm{t}, 120 \mathrm{~s}}, \mathrm{M}_{\max }$, and $\mathrm{M}_{120 \mathrm{~s}}$, distance to the bystander, ventilation intensity, and the tested products are presented in Supplementary Material (Fig. S2). Even if models lack statistical strength (especially with the ventilation intensity variable), they provide insights on the quantitative associations between variables in this particular setting. The case of $\mathrm{PNC}_{\mathrm{t} \text {,max }}$ demonstrates the limited effect of ventilation intensity, and establishes relationships

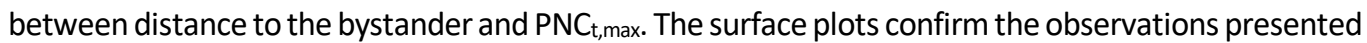
in above subchapters on a higher overall concentration levels while using EC, while these levels vary from $0.5 \mathrm{E}+06 \# \mathrm{~cm}^{-3}$ at $2 \mathrm{~m}$ distance and gradually increase to $6 \mathrm{E}+06 \mathrm{~cm}^{-3}$ at a $0.5 \mathrm{~m}$ distance. HTPs follows the same variation trend, but with lower levels of PNC. In case of PNC $\mathrm{C}_{t, 120 \mathrm{~s}}$ the distance and ventilation seems to have an equal role to the variation of concentration. Although ventilation variable lack statistical significance, this indicates that during longer timespans the ventilation may play important role in reducing concentration levels. These two engineering measures may be coupled together in managing potential exposure to bystanders if these products are consumed in a closed environment. Such as, together these measures at maximum settings are capable in reducing PNC levels by $20 \%$, while each of them contribute equally by $10 \%$.

Similar trend of both factors' influence is valid when predicting prevailing particle size distribution after $120 \mathrm{~s}$. Increasing ventilation and distance from bystander results in shrinking particles as an outcome of evaporation of volatile substances. Within the tested boundaries, we were not able to register an accumulation of HTP particles in a room; when the evaporation diminishes and 
concentrations starts increasing, considering that some exhaled HTP particles have non-volatile core. It may take more users to observe this effect (Meišutovič-Akhtarieva et al., 2019). For the reported conditions, we conclude that the dynamics of these particles follow rather similar patterns to the exhaled EC particles.

\section{CONCLUSIONS}

The comparison of the aerosol dynamics following the exhalation after using heated tobacco product (HTP) and vaping product (electronic cigarette - EC) indicates both similarities and differences between the two products, and both very distinct from conventional cigarettes.

The total particle number concentration during the usage of EC is higher, as is the concentration decay rate after the puff. The shrinkage of exhaled EC particles is also faster, owing to a more volatile nature of the exhaled aerosol. However, the particle size distributions as well as factors affecting their dispersion in a room affect both products in similar manner, indicating that while there may be differences in concentration levels or removal rates, the prevailing physical mechanisms of aerosol transport and transformations between HTP and EC exhaled aerosol are similar (i.e., shrinking of particle size due to evaporation), but different from tobacco burning products, such as conventional cigarettes. A lot of uncertainty in these processes is brought by the usage topography, which must either be strictly standardized in further investigations, or accepted as a major variable. Distance from a user to a bystander is the most important parameter to reduce short term exposure, while long term exposure should be managed by the synergy of ventilation intensity and distance from users to bystanders.

\section{ACKNOWLEDGMENTS}

Authors are grateful to Ms. Preethi Ravikumar and Mr. Oleh Pitak for the assistance in laboratory experiments.

\section{DISCLAIMER}

The research presented in this manuscript has been funded by Imperial Brands PLC.

\section{SUPPLEMENTARY MATERIAL}

Supplementary material for this article can be found in the online version at https://doi. org/10.4209/aaqr.200653

\section{REFERENCES}

Allen, J.G., Flanigan, S.S., LeBlanc, M., Vallarino, J., MacNaughton, P., Stewart, J.H., Christiani, D.C. (2016). Flavoring chemicals in e-cigarettes: Diacetyl, 2,3-pentanedione, and acetoin in a sample of 51 products, including fruit-, candy-, and cocktail-flavored e-cigarettes. Environ. Health Perspect. 124, 733-739. https://doi.org/10.1289/ehp.1510185

Bekki, K., Inaba, Y., Uchiyama, S., Kunugita, N. (2017). Comparison of chemicals in mainstream smoke in heat-not-burn tobacco and combustion cigarettes. J. UOEH. 39, 201-207. https://doi.org/10.7888/juoeh.39.201

Belka, M., Lizal, F., Jedelsky, J., Jicha, M., Pospisil, J. (2017). Measurement of an electronic cigarette aerosol size distribution during a puff. EPJ Web Conf. 143, 02006. https://doi.org/10. 1051/epjconf/201714302006

Bentley, M.C., Almstetter, M., Arndt, D., Knorr, A., Martin, E., Pospisil, P., Maeder, S. (2020). Comprehensive chemical characterization of the aerosol generated by a heated tobacco product by untargeted screening. Anal. Bioanal.Chem. 412, 2675-2685. https://doi.org/10.10 07/s00216-020-02502-1 
Bertholon, J.F., Becquemin, M.H., Annesi-Maesano, I., Dautzenberg, B. (2013). Electronic cigarettes: A short review. Respiration 86, 433-438. https://doi.org/10.1159/000353253

Braun, M., Koger, F., Klingelhöfer, D., Müller, R., Groneberg, D.A. (2019). Particulate matter emissions of four different cigarette types of one popular brand: Influence of tobacco strength and additives. Int. J. Environ. Res. Public Health 16, 263. https://doi.org/10.3390/ijerph16020263

Cancelada, L., Sleiman, M., Tang, X., Russell, M.L., Nahuel Montesinos, V., Litter, M.I., Gundel, L.A., Destaillats, H. (2019). Heated tobacco products: Volatile emissions and their predicted impact on indoor air quality. Environ. Sci. Technol. 53, 7866-7876. https://doi.org/10.1021/ac s.est.9b02544

Cozzani, V., Barontini, F., McGrath, T., Mahler, B., Nordlund, M., Smith, M., Schaller, J.P., Zuber, G. (2020). An experimental investigation into the operation of an electrically heated tobacco system. Thermochim. Acta 684, 178475. https://doi.org/10.1016/j.tca.2019.178475

Feng, Y., Kleinstreuer, C., Rostami, A. (2015). Evaporation and condensation of multicomponent electronic cigarette droplets and conventional cigarette smoke particles in an idealized G3-G6 triple bifurcating unit. J. Aerosol Sci. 80, 58-74. https://doi.org/10.1016/j.jaerosci.2014.11.002

Floyd, E.L., Queimado, L., Wang, J., Regens, J.L., Johnson, D.L. (2018). Electronic cigarette power affects count concentration and particle size distribution of vaping aerosol. PLoS One 13, e0210147. https://doi.org/10.1371/journal.pone.0210147

Gillman, G., Kistler, K.A, Stewart, E.W, Paolantonio A.R (2016). Effect of variable power levels on the yield of total aerosol mass and formation of aldehydes in e-cigarette aerosols. Regul. Toxicol. Pharm. 75, 58-65. https://doi.org/10.1016/j.yrtph.2015.12.019

Gillman, I.G., Pennington, A.S.C., Humphries, K.E., Oldham, M.J. (2020). Determining the impact of flavored e-liquids on aldehyde production during vaping. Regul. Toxicol. Pharm. 112, 104588. https://doi.org/10.1016/j.yrtph.2020.104588

Ilies, B.D., Moosakutty, S., Kharbatia, N., Sarathy, M. (2020). Expression of concern: Identification of volatile constituents released from IQOS heat-not-burn tobacco HeatSticks using a direct sampling method. Tobacco Control. https://doi.org/10.1136/tobaccocontrol-2019-055521

Jaccard, G., Tafin Djoko, D., Moennikes, O., Jeannet, C., Kondylis, A., Belushkin, M. (2017). Comparative assessment of HPHC yields in the Tobacco Heating System THS2.2 and commercial cigarettes. Regul. Toxicol. Pharm. 90, 1-8. https://doi.org/10.1016/j.yrtph.2017.08.006

Jurelionis, A., Gagytè, L., Prasauskas, T., Čiužas, D., Krugly, E., Šeduikytė, L., Martuzevičius, D. (2015). The impact of the air distribution method in ventilated rooms on the aerosol particle dispersion and removal: The experimental approach. Energy Build. 86, 305-313. https://doi.org/10.1016/j.enbuild.2014.10.014

Kaunelienè, V., Meišutovič-Akhtarieva, M., Martuzevičius, D. (2018). A review of the impacts of Tobacco Heating System on indoor air quality versus conventional pollution sources. Chemosphere 206, 568-578. https://doi.org/10.1016/j.chemosphere.2018.05.039

Kaunelienė, V., Meišutovič-Akhtarieva, M., Prasauskas, T., Čiužas, D., Krugly, E., Keraitytė, K., Martuzevičius, D. (2019). Impact of using a Tobacco Heating System (THS) on indoor air quality in a nightclub. Aerosol Air Qual. Res. 19, 1961-1968. https://doi.org/10.4209/aaqr.2019.04.0211

Li, L., Lee, E.S., Nguyen, C., Zhu, Y. (2020). Effects of propylene glycol, vegetable glycerin, and nicotine on emissions and dynamics of electronic cigarette aerosols. Aerosol Sci. Technol. 54, 1270-1281. https://doi.org/10.1080/02786826.2020.1771270

Long, G.A. (2014). Comparison of select analytes in exhaled aerosol from e-cigarettes with exhaled smoke from a conventional cigarette and exhaled breaths. Int. J. Environ. Res. Public Health 11, 11177-11191. https://doi.org/10.3390/ijerph111111177

Loupa, G., Karali, D., Rapsomanikis, S. (2019). The trace of airborne particulate matter from smoking e-cigarette, Tobacco Heating System, conventional and hand-rolled cigarettes in a residential environment. Air Qual. Atmos. Health 12, 1449-1457. https://doi.org/10.1007/s11 869-019-00760-2

Martuzevicius, D., Prasauskas, T., Setyan, A., O'Connell, G., Cahours, X., Julien, R., Colard, S. (2019). Characterization of the spatial and temporal dispersion differences between exhaled e-cigarette mist and cigarette smoke. Nicotine Tob. Res. 21, 1371-1377. https://doi.org/10.10 93/ntr/nty121

Meišutovič-Akhtarieva, M., Prasauskas, T., Čiužas, D., Krugly, E., Keraitytė, K., Martuzevičius, D., Kaunelienè, V. (2019). Impacts of exhaled aerosol from the usage of the Tobacco Heating 
System to indoor air quality: A chamber study. Chemosphere 223, 474-482. https://doi.org/1 0.1016/j.chemosphere.2019.02.095

Mikheev, V.B., Brinkman, M.C., Granville, C.A., Gordon, S.M., Clark, P.I. (2016). Real-time measurement of electronic cigarette aerosol size distribution and metals content analysis. Nicotine Tob. Res. 18, 1895-1902. https://doi.org/10.1093/ntr/ntw128

Mitova, M.I., Campelos, P.B., Goujon-Ginglinger, C.G., Maeder, S., Mottier, N., Rouget, E.G.R., Tharin, M., Tricker, A.R. (2016). Comparison of the impact of the Tobacco Heating System 2.2 and a cigarette on indoor air quality. Regul. Toxicol. Pharm. 80, 91-101. https://doi.org/10.101 6/j.yrtph.2016.06.005

Mitova, M.I., Bielik, N., Campelos, P.B., Cluse, C., Goujon-Ginglinger, C.G., Jaquier, A., Gomez Lueso, M., Maeder, S., Pitton, C., Poget, L., Polier-Calame, J., Rotach, M., Rouget, E.G.R., Schaller, M., Tharin, M., Zaugg, V. (2019). Air quality assessment of the Tobacco Heating System 2.2 under simulated residential conditions. Air Qual. Atmos. Health 12, 807-823. https://doi.org/10.1007/s11869-019-00697-6

Noël, A., Verret, C.M., Hasan, F., Lomnicki, S., Morse, J., Robichaud, A., Penn, A.L. (2018). Generation of electronic cigarette aerosol by a third-generation machine-vaping device: Application to toxicological studies. J. Visualized Exp. 2018, e58095. https://doi.org/10.3791/5 8095

O'Connell, G., Colard, S., Breiev, K., Sulzer, P., Biel, S. (2015). An experimental method to determine the concentration of nicotine in exhaled breath and its retention rate following use of an electronic cigarette. J. Environ. Anal. Chem. 2, 161. https://doi.org/10.4172/23802391.1000161

Pacitto, A., Stabile, L., Scungio, M., Rizza, V., Buonanno, G. (2018). Characterization of airborne particles emitted by an electrically heated Tobacco Smoking System. Environ. Pollut. 240, 248254. https://doi.org/10.1016/j.envpol.2018.04.137

Palmisani, J., Di Gilio, A., Palmieri, L., Abenavoli, C., Famele, M., Draisci, R., de Gennaro, G. (2019). Evaluation of second-hand exposure to electronic cigarette vaping under a real scenario: measurements of ultrafine particle number concentration and size distribution and comparison with traditional tobacco smoke. Toxics 7, 59. https://doi.org/10.3390/toxics7040059

Protano, C., Manigrasso, M., Cammalleri, V., Zoccai, G.B., Frati, G., Avino, P., Vitali, M. (2020) Impact of electronic alternatives to tobacco cigarettes on indoor air particular matter levels. Int. J. Environ. Res. Public Health 17, 2947. https://doi.org/10.3390/ijerph17082947

Ruprecht, A.A., De Marco, C., Saffari, A., Pozzi, P., Mazza, R., Veronese, C., Angellotti, G., Munarini, E., Ogliari, A.C., Westerdahl, D., Hasheminassab, S., Shafer, M.M., Schauer, J.J., Repace, J., Sioutas, C., Boffi, R. (2017). Environmental pollution and emission factors of electronic cigarettes, heat-not-burn tobacco products, and conventional cigarettes. Aerosol Sci. Technol. 51, 674-684. https://doi.org/10.1080/02786826.2017.1300231

Schaller, J.P., Pijnenburg, J.P.M., Ajithkumar, A., Tricker, A.R. (2016). Evaluation of the Tobacco Heating System 2.2. Part 3: Influence of the tobacco blend on the formation of harmful and potentially harmful constituents of the Tobacco Heating System 2.2 aerosol. Regul. Toxicol. Pharm. 81, S48-S58. https://doi.org/10.1016/j.yrtph.2016.10.016

Smith, M.R., Clark, B., Lüdicke, F., Schaller, J.P., Vanscheeuwijck, P., Hoeng, J., Peitsch, M.C. (2016). Evaluation of the Tobacco Heating System 2.2. Part 1: Description of the system and the scientific assessment program. Regul. Toxicol. Pharm. 81, S17-S26. https://doi.org/10.101 6/j.yrtph.2016.07.006

Uchiyama, S., Noguchi, M., Takagi, N., Hayashida, H., Inaba, Y., Ogura, H., Kunugita, N. (2018). Simple determination of gaseous and particulate compounds generated from heated tobacco products. Chem. Res. Toxicol. 31, 585-593. https://doi.org/10.1021/acs.chemrestox.8b00024

World Health Organization (WHO) (2019). WHO Report on the Global Tobacco Epidemic: Offer to Help Quit Tobacco Use. https://escholarship.org/uc/item/1g16k8b9 (accessed 07 November 2020).

Zhao, J., Nelson, J., Dada, O., Pyrgiotakis, G., Kavouras, I.G., Demokritou, P. (2018). Assessing electronic cigarette emissions: linking physico-chemical properties to product brand, e-liquid flavoring additives, operational voltage and user puffing patterns. Inhalation Toxicol. 30, 7888. https://doi.org/10.1080/08958378.2018.1450462

Zhao, T., Nguyen, C., Lin, C.H., Middlekauff, H.R., Peters, K., Moheimani, R., Guo, Q., Zhu, Y. 
ORIGINAL RESEARCH

(2017). Characteristics of secondhand electronic cigarette aerosols from active human use. Aerosol Sci. Technol. 51, 1368-1376. https://doi.org/10.1080/02786826.2017.1355548 